\title{
Dental Care Interventions as Efforts to Reduce PUFA Index and Improve Nutritional Status in Children aged 9-12 Years in Orphanages
}

\author{
Indrayati Fadjeri $^{1}$, Rahaju Budiarti ${ }^{1}$, Tedi Purnama ${ }^{1}$ \\ ${ }^{I}$ Assistant Professor, Department of Dental Health, Health Polytechnic of Jakarta I, Indonesia
}

\begin{abstract}
The main problem in the child's oral cavity to date is dental caries. Untreated dental caries could cause difficulty eating and sleeping, experience pain, and need continuous care, so that it impacts on poor quality of life, and health problems arise one of which is the condition of the child's nutritional status. This research aims at effectiveness Dental Care Interventions as Efforts to Reduce PUFA Index and Improve Nutritional Status in Children aged 9-12 Years in Orphanages. Method: this study used a quasy experiment with a pretest and posttest with control group design. This research was conducted at the Mizan Amanah Orphanage in Cinere District, Depok City. Independent variable: Dental care intervention and dependent variable: PUPA index and children's nutritional status. Data tested using Wilcoxon/paired sample t-test and independent t-test/mann whitney test and linear regression. Results: Dental care interventions were effective in reducing PUPA index $(\mathrm{p}<0.001)$ and were effective in improving the status of children aged 9-12 years $(\mathrm{p}<0.011)$. Conclusion: effective dental care interventions as efforts to reduce PUPA index and nutritional status of children aged 9-12 years in orphanages
\end{abstract}

Keywords: Dental care interventions, PUFA Index, nutritional status.

\section{Introduction}

The main problem in the child's oral cavity to date is dental caries. This was proven by Nelwan research (2015) in Yataama Al Firdausi orphanage Semarang, showing the prevalence of dental caries by $69.7 \%$ while the results of the 2013 Basic Health Research reported the prevalence of Indonesian population with oral and dental health problems of $25.9 \%$. So it can mean the orphanage children have higher caries. ${ }^{2-4}$ In some countries the prevalence of dental caries has decreased in the last twenty-five years, but in developing countries, including Indonesia, the disease is still a major problem in adults and especially in children. ${ }^{5}$

\section{Corresponding Author:}

\section{Tedi Purnama}

Department of Dental Health, Health Polytechnic of Jakarta I, Wijaya Kusuma Raya Street, No. 47, Jakarta, Indonesia

e-mail: tedypurnama23@yahoo.com
A study in Delhi India of 520 children aged 9-12 years published in 2011 showed a caries prevalence of $52.3 \%$, the mean def-t for children aged 9 years was 2.17 and age 12 years was 0.27 ; while the average DMF-t of 9-year-old children is 1.1 and the age of 12 years is 0.8. Other studies in Peru showed the mean DMF-T of 12-year-old children was 3.92 with a caries prevalence of $83.8 \%{ }^{6-7}$

Caries is an infectious disease that results from bacterial interactions. Dental caries occurs due to the demineralization process of bacterial interactions on the tooth surface. Bacteria are acidic so that within a certain period of time, acids will damage tooth enamel and cause cavities. The etiological factors for caries are plaque microorganisms, diet and time. ${ }^{8}$

Untreated dental caries can cause difficulty eating and sleeping, experience pain, and need continuous care, thus impacting on poor quality of life, and health problems arise. One of them is the condition of the nutritional status of children. Children who experience dental caries will experience pain in the hole, so that it 
will reduce consumption of food. Children who reduce food consumption in the long term, will have an impact on the nutritional status of children. ${ }^{9}$

According Rohmawati (2016) dental caries is a disease that can interfere with the nutritional conditions of children so that it can cause nutritional problems. Dental caries is a disease that can interfere with the nutritional condition of children so that it can cause nutritional problems, with nutritional status but can also be related to the severity of dental caries. ${ }^{10}$

Some problems that arise in untreated caries such as pulpitis, ulceration, fistula, abscess and pulp necrosis. The index used to calculate the severity of untreated dental caries is known as the PUFA index. In permanent teeth, this index is written using capital letters (PUFA) while milk teeth are written using lowercase letters (pufa). ${ }^{11,12}$

Siregar research (2019) showed the severity of untreated dental caries that had caused an open pulp $(\mathrm{P} / \mathrm{p})$ of 1.54; traumatic ulceration around soft tissue $(\mathrm{U} / \mathrm{u})$ on average by 0.06 ; there is no severity of untreated dental caries that has caused fistulas $(\mathrm{F} / \mathrm{f})$; and has caused inflammation or abscess (A/a) of 0.07 on average. Another study by Pratiwi (2013) also proved the overall prevalence of caries at the age of 6 years by $62 \%$ with the highest component of caries in deciduous teeth and 8 permanent teeth had caries with pulp involvement. For the age of 9 years $65.8 \%$ with permanent dental caries $10 \%$ and children aged 12 years the highest caries prevalence in permanent teeth, which is $25.3 \% .^{5,11}$

Efforts are made to overcome the problem of dental and oral diseases by approaching health workers and dentists in the form of dental and oral health services in the form of activities with promotive, preventive, curative approaches, which are carried out in an integrated, comprehensive, and sustainable manner. Dental care interventions to reduce PUPA index are dental fillings and extractions. It is expected that the pain caused by dental caries can be overcome and the function of chewing can function optimally so that the intake of nutrients is good and can affect the nutritional status of children. ${ }^{3}$

Based on background above author interested in conducting research under the title "Dental Care Interventions as an Effort to Reduce PUFA Index and Improve Nutritional Status in Children Aged 9-12 Years in Orphanages"

\section{Method}

The method used in this research is quasy experiment with pre and post-test with control group design. This research was conducted at Amanah Mizan Orphanage in Cinere District, Depok City. The data collection was carried out in August - September 2019. The research sample was taken using a purposive sampling technique, consisting of 62 respondents consisting of an intervention group of 32 respondents and a control of 32 respondents. The independent variables in this study were dental care interventions and the dependent variables were PUPA index and children's nutritional status. Research data using ratio scale, statistical tests using Wilcoxon/paired sample t-test and independent t-test/Mann Whitney test and linear regression. The research stages are as follows:

1. Respondents were selected according to criteria

2. Samples were divided into 2 groups, the intervention group was given dental care measures and the control group was only given mouth rinses.

3. Before examining the oral cavity we provide counseling on how to maintain healthy teeth and what are the effects if cavities are not treated.

4. The next step is to conduct a pre-test in the form of examination of PUFA index and nutritional status in the form of body mass index measurement.

5. Then the research intervention was carried out, in the intervention group the form of treatment performed was tooth extraction and dental fillings using mashed garlic and covered with temporary fillings. Whereas the control group gargled with warm salt solution.

6. After 30 days, a post-test was conducted to examine the PUFA index and nutritional status in the form of a body mass index measurement.

\section{Result}

Table 1. Frequency distribution of respondent characteristics

\begin{tabular}{|l|c|c|c|c|}
\hline \multirow{2}{*}{ Variable } & \multicolumn{2}{|c|}{ Intervention } & \multicolumn{2}{c|}{ Control } \\
\cline { 2 - 5 } & $\mathbf{N}$ & $\mathbf{\%}$ & $\mathbf{N}$ & $\mathbf{\%}$ \\
\hline Gender & 15 & 46.9 & 17 & 53.1 \\
\hline Men & 17 & 53.1 & 15 & 46.9 \\
\hline Women & 15 & 46.9 & 14 & 43.8 \\
\hline Age (Years) & 17 & 53.1 & 18 & 56.3 \\
\hline $11-10$ &
\end{tabular}


Table 1 shows the respondents in this study consisted of 34 men (53.12\%) and 30 women (46.88\%). The intervention group consisted of 15 men $(46.9 \%)$ and 17 women $(53.1 \%)$ while the control group consisted of 17 men $(53.1 \%)$ and 15 women $(46.9 \%)$. The age variable found that children aged 9-10 years amounted to 15 people in the intervention group and 14 people in the control group. While respondents aged 11-12 years there were 17 people in the intervention group and 18 people in the control group.

Table 2. Average PUPA index values and Nutrition Status

\begin{tabular}{|c|c|c|c|c|c|}
\hline \multirow{2}{*}{ No } & \multirow{2}{*}{ Variable } & \multicolumn{2}{|c|}{ Intervention } & \multicolumn{2}{|c|}{ Control } \\
\hline & & Pre-test & Post-test & Pre-test & Post-test \\
\hline \multirow[t]{4}{*}{1} & PUPA index & & & & \\
\hline & Mean & 1.44 & 0.47 & 1.28 & 1.09 \\
\hline & SD & 1,076 & 089 & 1,746 & 1,532 \\
\hline & Min-Max & $0-5$ & $0-4$ & $0-7$ & $0-6$ \\
\hline \multirow[t]{4}{*}{2} & Nutritional status & & & & \\
\hline & Mean & 17.55 & 17.77 & 16.14 & 16.36 \\
\hline & SD & 2,363 & 2,295 & 2,462 & 2,250 \\
\hline & Min-Max & $13.2-22.4$ & $13.5-22.8$ & $9.8-21.1$ & $10-20.8$ \\
\hline
\end{tabular}

Table 2 shows, the average PUFA index in the intervention group was 1.44 before treatment and in the control group was 1.28 , which means that there were an average of 2 cavities that were not treated. After dental treatment in the form of dental fillings and extractions, the average PUFA was found to decrease to 0.47 in the intervention group while in the control group it was 1.09. This table also shows changes in nutritional status in the intervention group on average 17.55 before treatment and there is an increase in nutritional status to an average of 17.77. Whereas in the control group the average nutritional status was 16.14 and after treatment it was 16.36 .

Table 3. Test the effectiveness of the PUPA index and nutritional status before and after dental care interventions

\begin{tabular}{|c|c|c|c|c|c|}
\hline \multirow{2}{*}{\multicolumn{2}{|c|}{ Group }} & \multicolumn{2}{|c|}{ PUPA Index * } & \multicolumn{2}{|c|}{ Nutritional status** } \\
\hline & & Mean + SD & P-value & Mean + SD & P-value \\
\hline \multirow{2}{*}{ Intervention } & Pre-test & $1.44+1,076$ & \multirow{2}{*}{0.001} & $17.55+2,363$ & \multirow{2}{*}{0.011} \\
\hline & Post-test & $0.47+0.879$ & & $17.77+2,295$ & \\
\hline \multirow{2}{*}{ Control } & Pre-test & $1.28+1.746$ & \multirow{2}{*}{0.064} & $16.14+2.462$ & \multirow{2}{*}{0.168} \\
\hline & Post-test & $1.09+1.532$ & & $16.36+2.250$ & \\
\hline
\end{tabular}

* Wilcoxon, ** Paired Test Samples

The results of effectiveness test data before and after dental treatment showed PUPA index p-value of the intervention group was $0.003(\mathrm{p}<0.05)$ and the control group's p-value was 0.064 ( $\mathrm{p}>0.05)$ while the nutritional status showed the intervention group's p-value was $0.011(\mathrm{p}<0.05)$ and the $\mathrm{p}$-value of the control group was $0.168(\mathrm{p}>0.05)$ meaning that the administration of dental care interventions effectively increased the PUPA index of nutritional status in children of the Mizan Amanah orphanage. 
Table 4. Different tests of PUPA index and Nutrition Status in the intervention and control groups

\begin{tabular}{|l|l|c|c|c|c|}
\hline \multirow{2}{*}{ Group } & \multicolumn{2}{|c|}{ PUPA Index * } & \multicolumn{2}{c|}{ Nutritional status** } \\
\cline { 5 - 6 } & Pre-test & \multirow{2}{*}{$0.47+0.879$} & & Mean + SD & P-value \\
\cline { 2 - 2 } Intervention & Post-test & & \multirow{2}{*}{0.050} & $17.77+2,295$ & \multirow{2}{*}{0.015} \\
\cline { 2 - 2 } Control & Pre-test & \multirow{2}{*}{$1.09+1.532$} & & $16.36+2,250$ & \\
\cline { 2 - 2 } & Post-test & & & \\
\hline
\end{tabular}

* Mann-Whitney, ** Independent Sample Test

The results of the PUPA index difference test showed the $\mathrm{p}$-value between the intervention group and the control group was $0.050(\mathrm{p}<0.05)$, meaning that the provision of dental care interventions was more effective in increasing the PUPA index than the control group.
While the nutritional status shows the p-value between the intervention and control groups is $0.015(\mathrm{p}>0.05)$ meaning that the provision of dental care interventions is more effective in improving nutritional status compared to the control group.

Table 5. Dental care most influential on nutritional status

\begin{tabular}{|l|c|c|c|c|c|}
\hline Variable & B & P value & R Square & C & Annova P-value \\
\cline { 1 - 3 } Dental filling & 1,083 & 0.145 & 0.177 & \multirow{2}{*}{19.28} & 0.05 \\
\cline { 1 - 3 } Tooth extraction & 1,502 & 0.025 & & \\
\hline
\end{tabular}

* Linear regression

Based on table 5, it can be seen that the constant value is 19.28 with a dental filling coefficient of 1.083 meaning that a $1 \%$ dental filling intervention will increase nutritional status by 1,083 . The tooth extraction coefficient value of 1.502 means that the $1 \%$ tooth extraction intervention will increase the nutritional status by 1,502 . The results of the analysis show the results of R2 (R Square) of 0.177 or (17.7\%), meaning that dental filling and tooth extraction interventions have a $17.7 \%$ effect on improving nutritional status. The analysis showed that the value of $p=0.05$ means that the influence of dental filling intervention and tooth extraction has an increase in nutritional status.

\section{Discussion}

Nutrition is food intake related to the body's need for food. Adequate nutrition includes quality, quantity, and the body's ability to use it carefully to meet the body's metabolic needs. With many cases of cavities that are not treated immediately will cause pain and discomfort when eating which can result in decreased appetite that will affect body mass index. ${ }^{13,14}$
The results of the test of the effectiveness of data before and after being given dental care showed a value of $p<0.05$. This situation shows that by decreasing cases of untreated caries (PUFA index) by treating dental problems can improve the nutritional status of children. This situation is in line with research conducted by Rohmawati (2016), which states that there is a significant relationship between the caries index that is not treated with nutritional status. This can happen because if a tooth is damaged or disrupted it will interfere with the function of mastication and will tend to choose soft foods so that it will reduce the intake of nutrients that will affect the child's weight. ${ }^{10,13}$

The results of the analysis of the types of treatments that are most effective for obtaining nutritional status show that both dental care interventions, either tooth extraction or dental fillings can reduce the pain that may

arise when they consume food so that there is no more interference when teeth are used for masticatory function, this condition allows increased food intake which can improve nutritional status. In accordance with secondary factors that affect nutritional status, 
namely the presence of impaired digestive function of food such as tooth decay/disease, the digestive apparatus that causes food cannot be digested properly, so that incoming nutrients cannot be absorbed properly resulting in insufficient body needs. ${ }^{10,15}$

Judging from the type of treatment, dental filling interventions provide changes in nutritional status better when compared to treatment of extraction. In the case of filling most of the cavities are already on the pulp, causing pain when used for chewing and after filling the pain is reduced so that it can perform mastication function is better and there is an increase in nutritional status. Patches made to close cavities using garlic ingredients to reduce pain and were quite effective for a while, because it can also improve the nutritional status of children. ${ }^{16}$ Nevertheless dental care must be continued for permanent fillings.

\section{Conclusion}

\section{Based on the results of the study, it can be concluded that:}

1. Dental care interventions were proven to be significantly $(p<0.001)$ effective in increasing the PUPA index of children in the Mizan Amanah orphanage.

2. Dental care interventions were shown to be significantly $(p<0.001)$ effective in improving the nutritional status of Mizan Amanah orphanages.

3. Dental care interventions in the form of dental fillings and extractions have a $17.7 \%$ effect on improving nutritional status.

Source Funding: This study was funded by Ministry of Health Polytechnic Jakarta I.

Conflict of Interest: The authors declare that they have no conflict interests.

Ethical Clearance: The ethical clearance taken from Ethical Committee of Health Research, Health Polytechnic of Jakarta I.

\section{Refference}

1 Gultom E, Sormin T. Analysis of Dental Health Status and Dental Care Needs of Elementary School Students in Bandar Lampung City. Sai Betik's Scientific Nursing Journal. 2018; 13 (1): 67-74.

2 Purnama T, Rasipin R, Santoso B. Effects of Tedi's
Behavior Change Model Training on Teachers and Parents on Teeth Brushing Skills of Preschoolers. Journal of Health Quality. 2019; 13 (2): 75-81.

3 Nelwan J. FActors - Factors That Influence the High Case of Dental Caries in Children of Yataama AL-Firdausi Orphanage in the Work Area of the Ngesrep Health Center in 2011. Journal of Dental Health. 2015; 3 (2): 106-12.

4 Ministry of Health. Basic health research (Riskesdas) 2013. 2013.

5 Pratiwi R, Mutmainah R. A description of the Severity of Caries in Children Ages 6, 9 and 12 Years in Pinrang Regency, South Sulawesi Using the PUFA/pufa index. A Dentofacial. 2013; 2.

6 Mathur A, Mathur A, Jain M, Shah P, Pareek V, Prabu D, et al. Dental caries experience among kindergarten school going children of, India. Pediatric Dental Journal. 2011; 21 (1): 1-5.

7 Delgado-Angulo EK, Hobdell MH, Bernabe E. Poverty, social exclusion and dental caries of 12-year-old children: a cross-sectional study in Lima, Peru. BMC oral health. 2009; 9 (1): 16.

8 Mustika MD. Incidence of Dental Caries in Preschoolers in Red Kindergarten Meranggi Marta Pura. Dentino Journal of Dentistry. 2014; 2 (2).

9 Putri RM, Maemunah N, Rahayu W. The Relationship of Dental Caries with the Nutritional Status of Preschoolers. Care: Scientific Journal of Health Sciences. 2017; 5 (1): 28-40.

10 Rohmawati N. Dental Caries and Child Nutritional Status. Stomatognatic-Journal of Dentistry. 2017; 13 (1): 32-36.

11 Siregar SNA, Molek K. Severity of Untreated Caries in Class 1, 2, and 3 Children in Parulian 2 Elementary School in Medan Based on PUFA Index/puff. Prima Journal of Oral and Dental Sciences. 2019; 2 (6): 1-6

12 Jotlely FB, Wowor VN, Gunawan PN. The caries status is based on the DMF-T index and the PUFA index for Papuans in the Cendrawasih hostel in the city of Manado.Journal of e-Dentistry. 2017; 5 (2).

13 Asmawati PF, Pasolon F. Analysis of the relationship of dental caries and nutritional status of children aged 10-11 years in Athirah Elementary School, SDN 1 Bawakaraeng and SDN 3 Bangkala. Dentofacial Journal. 2007; 6 (2): 78-84.

14 Fankari F. Relationship between Dental Caries 
Occurrence Rate and Nutritional Status of Children 6-7 Years at SD Inpres Kaniti, Kupang Tengah District, Kupang Regency. Journal of Health Info. 2018; 16 (1): 32-43.

15 Par'i H, Wiyono S, Harjatmo T. Nutrition teaching materials: assessment of nutritional status. Ministry of Health of the Republic of Indonesia. 2017.
16 Soraya C, Chismirina S, Novita R. Effect of Garlic Juice (Allium sativum L.) As Root Canal Irrigation In Inhibiting Growth of Enterococcus faecalis In Vitro. Cakradonya Dental Journal. 2018; 10 (1): 1 